4.

Derecho CONSTITUCIONAL 



\title{
LAS CATEGORÍAS SOSPECHOSAS EN EL DERECHO CHILENO
}

\author{
[Suspect classifications in chilean law]
}

\author{
José Manuel Díaz de Valdés J.* \\ Universidad del Desarrollo
}

\begin{abstract}
RESUMEN
ABSTRACT

Se analiza la noción de categorías sospechosas, postulando su incompleta incorporación en el derecho chileno. Se comienza intentando precisar el concepto, ofreciendo una definición y discurriendo acerca de sus características y efectos. Luego se examina su falta de consagración en la Constitución y en la legislación. Finalmente, se analiza críticamente su incipiente utilización por el Tribunal Constitucional.

Palabras clave

Categorías Sospechosas Discriminación - Justicia Constitucional - Igualdad.

ABSTRACT
This text analyses the notion of
suspect classifications, arguing that its
reception in Chilean law is incomplete.
First, there is an attempt to clarify
this concept, offering a definition and
discussing its characteristics and effects.
Then, this work examines the lack of
constitutional or statutory recognition of
these classifications. Finally, it critically
analyses the emerging use of such
classifications by the Constitutional
Court.
S KeY wORDS
Discrimination - Constitutional Justice
- Equality.

Recibido el 12 de septiembre de 2017 y Aprobado el 15 de julio de 2018

* Doctor en Derecho (Universidad de Oxford). Director del Centro de Justicia Constitucional de la UDD. Profesor de Derecho Constitucional UDD y PUC. Dirección postal: Avenida 80, Santiago, Chile, Dirección electrónica: jdiazdevaldes@ udd.cl. Este artículo se enmarca en el proyecto FONDECYT de Iniciación en Investigación, folio $N^{\circ}$ 11140287. Agradezco a mis ayudantes, señores Francisco Rivadeneira Domínguez y Álvaro Torres Bustamante.
\end{abstract}




\section{INTRODUCCIÓN}

La creciente preocupación de la comunidad jurídica nacional por los temas de igualdad y no discriminación ha llevado a la paulatina incorporación en su lenguaje de una serie de términos y conceptos desarrollados por otros ordenamientos jurídicos. Es así como hemos comenzado a utilizar expresiones tales como discriminación estructural, discriminación positiva, multidiscriminación, entre otras.

En este contexto, el concepto de categorías sospechosas, también denominadas clasificaciones o características sospechosas, o incluso prohibidas, ha recibido creciente atención, respondiendo a una concepción de igualdad que, más allá de la división formal/sustancial, se centra en grupos más que en individuos.

La hipótesis central de este artículo, sin embargo, es que las categorías sospechosas no han sido propiamente incorporadas al derecho chileno. Para comprobar lo anterior, se analiza el tratamiento otorgado a esta noción por las principales fuentes del derecho nacional.

El artículo se compone de tres partes. La primera intenta presentar una visión coherente de lo que son las categorías sospechosas y cuáles son los efectos o consecuencias de su utilización. La segunda aborda su tratamiento por la Constitución Política de la República (la "Constitución") y la legislación nacional. La tercera y última parte analiza en detalle la incipiente jurisprudencia constitucional sobre la materia.

\section{LAS CATEGORÍAS SOSPECHOSAS}

\section{1. ¿Qué son y cómo se determinan?}

Entendemos por categorías sospechosas aquellas características o rasgos personales que, como regla general, no deben utilizarse para establecer diferencias entre individuos, tales como la raza, el sexo y la religión, y que el ordenamiento jurídico ha señalado especialmente como indiciarios de discriminación arbitraria ${ }^{1}$. Tal y como su nombre indica, el empleo de tales categorías resulta "sospechoso" per se en razón de una probable dis-

${ }^{1}$ Definiciones en Besson, Samantha, Evolutions in non-discrimination law within the ECHR and the ESC systems: It takes two to tango in the council of Europe, en The American Journal of Comparative Law 60 (2012), 1, pp. 165-166; GERARDS, Janneke, The discrimination grounds of article 14 of the European convention on Human Rights, en Human Rights Law Review 13 (2013), 1, p. 116; FisHKIn, Joseph, Bottlenecks. A New Theory of Equal Opportunity (Oxford, Oxford University Press, 2014), p. 237; Courtis, Christian, Dimensiones Conceptuales de la Protección Legal contra la Discriminación, en Revista Derecho del Estado (2010), 24, p. 115; DíAZ, Iván, Ley 
criminación. Ello no significa, claro está, que toda discriminación exija la presencia de una categoría sospechosa ${ }^{2}$.

El origen del concepto es norteamericano, y se vincula fuertemente a la lucha librada en ese país por la igualdad racial y en contra de la existencia de minorías "insulares y relegadas en el sistema político"3.

Un elemento esencial de las categorías sospechosas es el énfasis que adquieren los grupos como sujetos de discriminación (no toda discriminación es reconducible a la pertenencia a un grupo $)^{4}$. Es así como estas categorías permiten clasificar a las personas en conjuntos tales como blancos, negros, católicos, mormones, judíos, etc. Lo anterior no significa, sin embargo, que todo criterio cuya aplicación permita constituir grupos sea una clasificación sospechosa, ya que se trata de una relación género-especie.

En cuanto a los listados de categorías sospechosas, estos pueden variar de sistema en sistema, sin perjuicio de que algunas clasificaciones tiendan a repetirse con mayor frecuencia, tales como la raza, el sexo y la religión ${ }^{5}$. La razón de esta diversidad de listados es una materia controversial ${ }^{6}$. Bajo una visión, se trataría de una cuestión netamente política, esto es, aquellos grupos desaventajados que logran una mayor influencia en el proceso de toma de decisiones obtendrían esta protección especial ${ }^{7}$. En contraste, desde una perspectiva dogmática, se ha intentado destilar ciertos requisitos o elementos comunes a toda categoría sospechosa, sin negar la presencia de un factor contextual relevante (la calificación de una característica

chilena contra la discriminación. Una evaluación desde los derechos internacional y constitucional, en Revista Chilena de Derecho 40 (2013), 2, p. 643.

2 Véase Gerards, Janneke, The discrimination, cit. (n. 1), pp. 118-119; ARNARDÓtTIR, Oddný, Multidimensional equality from within, en SHIEK, Dagmar y Chege, Victoria (editores), European Union Non-discrimination law (Nueva York, Routledge-Cavendish, 2009), pp. 60-61.

3 Corte Suprema de los Estados Unidos, United States v. Carolene Prods. Co., 304 U.S. 144 (1938). Véase BAKER, Aaron, Proportional, not strict, scrutiny: Against a U.S. "Suspect Classifications" model under Article 14 ECHR in the U.K., en The American Journal of Comparative Law 56 (2008), 4, p. 868 y ss.; GERARDS, Janneke, The discrimination, cit. (n. 1), p. 114; MENDELSON, Wallace, $A$ note on a famaous legal footnote, en The Journal of Politics 25 (1963), 2, pp. 373-376; IÑIguEZ, Andrea, La noción de "categoría sospechosa" y el derecho a la igualdad ante la ley en la jurisprudencia del Tribunal Constitucional, en Revista de Derecho de la Universidad Católica de Valparaíso 43 (2014), 2, pp. 497-500.

${ }^{4}$ Contrastar con CourTis, Christian, cit. (n. 1), p. 114. Véase también FisHKIN, James, cit. (n. 1), p. 246.

5 BAYEFSKY, Anne, El principio de igualdad o no discriminacion en el derecho internacional, en Human Rights Law journal 11 (1990), 1-2, pp. 18-22.

${ }^{6}$ Fishkin, James, cit. (n. 1), p. 237.

${ }^{7}$ FishKin, James, cit. (n. 1), pp. 236-237 
como protegida supone una importante significancia socio-jurídica en el respectivo país $)^{8}$. Las propuestas han sido diversas ${ }^{9}$. Algunos acentúan el impacto sobre la dignidad humana, es decir, otorgar un tratamiento distinto en virtud de ciertas características personales constituiría, en sí mismo, un daño, estigma o insulto a la dignidad de las personas así mal $\operatorname{tratadas}^{10}$. Otros destacan la asociación entre estos criterios y la existencia de ciertas "castas" o grupos sistémicamente discriminados en una sociedad (como las personas de raza negra en Sudáfrica, o los católicos en Irlanda del Norte $)^{11}$. Bajo esta perspectiva, serían relevantes la extensión e intensidad de la discriminación sufrida ${ }^{12}$. Una visión algo diferente enfatiza el impacto del factor en cuestión sobre la situación real de una persona o grupo en la sociedad en que vive ${ }^{13}$, en particular sobre sus oportunidades ${ }^{14}$. Existen otros que destacan el carácter inmutable de estos factores ${ }^{15}$, ya sea porque estrictamente no es posible cambiarlos (como la raza), o sólo puede hacerse en forma muy excepcional (como el sexo). Esta visión, sin embargo, deja fuera al menos una de las categorías sospechosas "clásicas", cual es la religión. Por lo mismo, algunos lo han modificado para incluir dentro de los factores inmutables aquellos que no podrían variarse sin afectar severamente la identidad de la persona ${ }^{16}$.

La existencia de un elemento común a las categorías sospechosas es

${ }^{8}$ DulitzKY, Ariel, El principio de igualdad y no discriminación. Claroscuros de la jurisprudencia interamericana, en Anuario de Derechos Humanos (2007), 3, p. 18.

9 Véase Réaume, Denise, Discrimination and Dignity, en Lousiana Law Review 63 (2003), 3, pp. 660-661 ; GERARDS, Janneke, Intensity of Judicial Review in Equal Treatment Cases, en Netherlands International Law Review 51 (2004), 2, pp. 162169.

10 Nikolaidis, Charilaos, The right to equality in Europe human rights law (London, Routledge, 2014), p. 71. Véase también Howard, Erica, The Case for a Considered Hierarchy of Discrimination Grounds in EU Law, en Maastricht Journal of European and Comparative Law 13 (2006), 4, p. 458; Gerards, Janneke, The discrimination, cit. (n. 1), pp. 115-116; Huscroft, Grant, Discrimination, Dignity, and the Limits of Equality, en Otago Law Review 9 (2000), 4, p. 704.

${ }^{11}$ Dulitzky, Ariel, cit (n. 8), p. 17; Nikolaidis, Charilaos, cit. (n. 10), p. 71; Salvador, María, Las Medidas de Acción Positiva. Principio de Igualdad y Derechos Fundamentales, en SÁNCHEZ, Santiago (editor), En Torno a la Igualdady la Desigualdad (Madrid, Dykinson, 2009), pp. 36-37.

12 Véase Howard, Erica, cit. (n. 10), pp. 454-457.

13 Gerards, Janneke, The discrimination cit. (n. 1), pp. 115-116; Courtis, Christian, cit. (n. 1), p. 115.

${ }^{14}$ Fishrin, James, cit. (n. 1), p. 237.

15 DulitzKY, Ariel, cit. (n. 8), p. 17; Gerards, Janneke, Intensity cit. (n. 9), pp. 164-165.

${ }^{16}$ Howard, Erica, cit. (n. 10), p. 454. 
también relevante por razones de técnica legislativa. Aunque su excepcionalidad llevaría a preferir listados claros y taxativos, aquellos quedan siempre abiertos a la interpretación extensiva de los tribunales. De ahí la necesidad de contar con ciertos parámetros-elementos esenciales comunes a las clasificaciones sospechosas - que guíen a los tribunales en la inclusión de nuevas categorías, de modo que por muy abierta que sea la lista, aquella no sea extensible a cualquier $\cos ^{17}$.

\section{Efectos de las categorías sospechosas}

a) Efecto esencial y relación con los tests de discriminación arbitraria.Tal y como mencionamos, la utilización de uno o más de estos criterios debe hacer sospechar a quién controla la medida o norma en cuestión, normalmente el juez. ¿Sospechar qué? Que se encuentra frente a una discriminación arbitraria ${ }^{18}$. Por lo mismo, para permitir la vigencia de tal distinción, se le exige alcanzar un alto nivel de convencimiento de que no es arbitraria. En otras palabras, la utilización de la categoría debe justificarse en forma particularmente convincente de forma de despejar la sospecha que provoca per se.

Es así como se ha señalado que la mayor convicción exigida al juez implicará un examen más severo o intenso de la distinción en cuestión ${ }^{19}$. Ello es similar, pero no equivalente, a requerir "la revisión altamente intensiva y cuidadosa de la justificación de la diferencia de trato"20, o "un mayor cuidado en la fundamentación y resolución del recurso respectivo" 21 por parte del juez. Evidentemente, si aquel debe convencerse plenamente de la legitimidad de la diferencia, deberá revisar con especial cuidado las razones

17 Salvador, María, cit. (n. 11), pp. 37-38.

18 Gerards, Janneke, Grounds of discrimination, en SCHIEK, Dagmar, Waddington, Lisa y Bell, Mark (editores), Non-discrimination law (Portland, Hart, 2007), p. 36

19 Bayefsky, Anne, cit. (n. 5), p. 18; Courtis, Christian, cit. (n. 1), p. 107; Salvador, María, cit. (n. 11), pp. 37 y 42; Atria, Fernando, Los Peligros de la Constitución. La Idea de Igualdad en la Jurisdicción Nacional (Santiago, Escuela de Derecho Universidad Diego Portales, 1997), pp. 64-71; DíAz, Iván, cit. (n. 1), p. 645. Véase también SADURSKI, Wojciech, Equality and Legitimacy (Oxford, Oxford University Press, 2008), pp. 111-124; McCrudden, Christopher y PreChal, Sacha, The Concepts of Equality and Non-Discrimination in Europe: A practical approach (2009) [visible en internet: http://ec.europa.eu/social/BlobServlet?docId=4553] (2/7/2017), pp. 23-27. Un antecedente jurisdiccional ilustrativo en Tribunal Constitucional Español, STC 200/200 (4/10/2001).

${ }^{20}$ Gerards, Janneke, The discrimination, cit. (n. 1), p. 114 (traducción propia). Algo similar en BAYEFSKY, Anne, cit. (n. 5), p. 18.

${ }^{21}$ Atria, Fernando, cit. (n. 19), p. 68. 
ofrecidas por quién la realizó. También sería deseable que plasmara con esmero los razonamientos de su decisión. Pero nótese que nada de esto es esencial: el juez podría alcanzar su convencimiento recurriendo a otras fuentes y aún frente al silencio de quién realizó la diferencia. Y más que virtuosismo en la construcción de su sentencia, lo fundamental es el grado de convencimiento que se alcanzó.

Una precisión al efecto general antes descrito, si bien algo más controversial, consiste en reconocer distintas consecuencias para el uso las categorías sospechosas, según si la diferencia de trato en cuestión beneficia o perjudica al grupo que se desea proteger. Debemos recordar que las categorías sospechosas permiten dividir a las personas en dos o más grupos $^{22}$. El sexo, por ejemplo, clasifica la población en hombres y mujeres. La religión, en cambio, da lugar a numerosos conjuntos: católicos, musulmanes, judíos, etc. Ahora bien, dentro de estos grupos, al menos uno de ellos debe ser objeto de la discriminación que justifica la existencia de la categoría sospechosa (en el caso del sexo, serían las mujeres). Siguiendo con la precisión en estudio, no toda distinción realizada sobre la base de una clasificación protegida debería ser evaluada de la misma forma: sólo aquellas que refuerzan la vulnerabilidad de los grupos desaventajados quedarían sujetas a "sospecha" (y por tanto a un control judicial más exigente), mientras que aquellas que resultaren beneficiosas para tales grupos serían sometidas a un examen más laxo ${ }^{23}$.

No cabe duda que la distinción anterior tiene sentido en la medida que nos recuerda cuál es el fin, y a la vez el origen, de las categorías sospechosas. Ellas están para favorecer a ciertos grupos que necesitan una protección especial, y por tanto sería absurdo aplicarlas mecánicamente para beneficiar a los ya beneficiados. No obstante lo anterior, en la práctica puede ser difícil administrar un sistema de categorías sospechosas con diferentes efectos según el grupo que se afecte. Es así como en algunas ocasiones no es evidente que exista un beneficio o perjuicio, ya que un mero trato distinto no siempre será indiscutiblemente positivo o negativo para los afectados. Adicionalmente, existen situaciones en que no resulta claro qué grupo está siendo beneficiado o perjudicado. Más aún, la aplicación de este criterio puede ser confusa cuando existen más de dos grupos definidos por la categoría sospechosa, y la diferencia beneficia o perjudica a varios de ellos, siendo algunos más desaventajados y otros no tanto o en absoluto. A

${ }^{22}$ Véase la explicación de "cognate groups" en KhaITAN, Tarunabh, $A$ theory of discrimination law (Oxford, Oxford University Press, 2015), cap. 2.3.

${ }^{23}$ BRest, Paul, In Defense of the Antidiscrimination Principle, en Harvard Law Review 90 (1976), 1, pp. 16 y ss.; Sunstein, Cass, The Anticaste Principle, en Michigan Law Review 92 (1994) 8, pp. 2439-2452. 
mayor abundamiento, todas las situaciones anteriores plantean dificultades importantes en materia de prueba.

Ahora bien, un elemento distinguible, pero estrechamente relacionado a los efectos de las categorías sospechosas, consiste en los tests utilizados para determinar la existencia de una discriminación arbitraria. Recordemos que no toda distinción está prohibida por el derecho, ya que en general se permite brindar un trato diferente, siempre y cuando pueda justificarse. Para evaluar dicha justificación se pueden utilizar distintos tests, tales como la proporcionalidad y la racionalidad. Cualquiera sea el test escogido, sin embargo, su aplicación debe convencer al juez de que existen razones suficientes para permitir dicha diferencia, la que no sería entonces arbitraria o discriminatoria. Por tanto, cuando se utilizan categorías sospechosas, no es el test de control el que debiera cambiar -si bien ello ocurre en algunas jurisdicciones-, ni tampoco los componentes del mismo, sino el estándar o intensidad de convencimiento del juez. En efecto, los tests no solucionan la controversia por sí mismos. Lo que ellos hacen es entregarle al juez una metodología que le permitirá ordenar y modelar sus razonamientos, los que quedarán plasmados en forma coherente en una sentencia que, gracias a esa misma metodología, podrá a su vez ser controlada y evaluada por los diversos agentes jurídicos. En consecuencia, el test no sustituye al juez, sólo lo asiste. Por lo mismo, los jueces, al aplicar los tests, pueden alcanzar grados diversos de convencimiento respecto de si existe una discriminación arbitraria o no. Lo que hace la categoría sospechosa es afectar este último paso, señalándole al juez que si de la aplicación del test no quedó enteramente convencido de estar frente una diferencia de trato legítima, debe entender es una discriminación arbitraria ${ }^{24}$.

Sin embargo, existen ciertas jurisdicciones en que el uso de algunas categorías sospechosas efectivamente tiene por efecto cambiar el test que aplica el juez al conocer del caso. Es la situación de Estados Unidos, donde se diferencian tres tests a este respecto ${ }^{25}$. El más exigente es el "escrutinio estricto", el cual requiere que la medida impugnada sea cuidadosamente diseñada para alcanzar un fin estatal imperioso o muy persuasivo ${ }^{26}$. Este test se utiliza fundamentalmente cuando la categoría sospechosa es la raza

${ }^{24}$ Gerards, Janneke, The discrimination, cit. (n. 1), pp. 119-120.

25 STRAUSS, Marcy, Reevaluating Suspect Classifications, en Seattle University Law Review 35 (2011), 1, pp. 135-174; GERARDS, Janneke, Intensity, cit. (n. 9), pp. 144149; McColgan, Aileen, Discrimination, equality and the law (Oxford, Hart, 2014), p. 43.

${ }^{26}$ La expresión en inglés es "narrowly tailored to a compelling state interest", en Corte Suprema de los Estados Unidos, Wygant v. Jackson Board of Education, 476 U.S. 267, 274 (1986). 
y la nacionalidad. La segunda posibilidad es el "escrutinio intermedio", el cual requiere que la medida en cuestión promueva sustancialmente un fin estatal de importancia ${ }^{27}$. Se aplica en casos de sexo, y eventualmente género e "ilegitimidad" filial. El tercer test es la simple racionalidad, en que se requiere que la medida impugnada guarde una relación racional con el objetivo legítimo que se busca ${ }^{28}$. Este test se aplica a todos los demás casos que no caen dentro de los dos primeros tests.

Otro ejemplo del empleo de diversos tests, aunque menos evidente e incluso controversial ${ }^{29}$, lo provee la Corte Europea de Derechos Humanos, quién aplicaría una suerte de "escrutinio estricto" en ciertas ocasiones. Si bien el listado de características o factores "favorecidos" es objeto de discusión, se han mencionado la raza, el sexo, la religión, la nacionalidad y la orientación sexual ${ }^{30}$. Del mismo modo, se ha afirmado que el ordenamiento jurídico de Unión Europea también pareciera jerarquizar entre rasgos o características de discriminación, donde factores como la nacionalidad o la raza gozaría de una protección especial ${ }^{31}$.

A nuestro juicio, un cambio de test no es aconsejable ${ }^{32}$, ya que no sólo complica innecesariamente la labor del juez, sino que obliga a identificar cuándo se utilizará cada test. Ello puede ser sumamente complejo, particularmente si obliga a distinguir entre distintas categorías sospechosas para efectos de someterlas a distintos tests. Otra complicación adicional, como ocurre en la experiencia norteamericana, es que el escrutinio estricto se usa también en situaciones que no tienen relación alguna con la discriminación arbitraria, lo que obliga a desarrollar una suerte de "dogmática" en torno a cada test para determinar qué cuestiones, de la más diversa índole, pueden resolver ${ }^{33}$. Frente lo anterior, pareciera aconsejable utilizar un solo test, por

${ }^{27}$ La expresión en inglés es "substantially advance an important state interest", en Corte Suprema de los Estados Unidos, Craig v. Boren, 429 U.S. 190, 197 (1976).

${ }^{28}$ La expresión en inglés es "rational relationship to legitimate state purposes", en Corte Suprema de los Estados Unidos, San Antonio Independent School District $v$. Rodriguez, 411 U.S. 1 (1973).

${ }_{29}$ Véase BAKer, Aaron, cit. (n. 3), pp. 886-889; ArnardótTir, Oddný, cit. (n. 2), pp. 56-58.

${ }^{30}$ Véase Besson, Samantha, cit. (n. 1), p. 170; Howard, Erica, cit. (n. 10), pp. 458-460; McCrudden, Christopher y Prechal, Sacha, cit. (n. 19), pp. 26-27; Nikolaidis, Charilaos, cit. (n. 10), p. 71.

${ }^{31}$ Howard, Erica, cit. (n. 10), p. 445-470; MCCRUdden, Christopher y Prechal, Sacha, cit. (n. 19), pp. 25-26. En el ámbito interamericano, véase DulitzKY, Ariel, cit. (n. 8) pp. 16-24.

32 BaKer, Aaron, cit. (n. 3), pp. 847-893; STRAuss, Marcy, cit. (n.25), pp. 135174.

33 Véase Gerards, Janneke, Intensity, cit. (n. 9), pp. 153-181. 
lo menos en aquellas jurisdicciones en que este se aplica de forma rutinaria a todos los casos de no discriminación. Sería el caso de Chile, donde la razonabilidad es el test o estándar que ha sido tradicionalmente utilizado para lidiar con todo tipo de discriminaciones arbitrarias ${ }^{34}$. Es cierto que este test presenta una serie de inconvenientes, tales como la variación existente en torno a su estructura y nivel de exigencia; su relativa deferencia hacia el controlado ${ }^{35}$; su tolerancia a la sobreinclusión e infrainclusión (se permite el trato diverso a ciertas situaciones o personas que debieron haberse excluido del mismo o viceversa), entre otros. ${ }^{36}$ No obstante lo anterior, cabe reconocer que la razonabilidad es el test que mejor se aviene a la noción de discriminación arbitraria consolidada en nuestro país, cual es aquella diferencia que no es racional, o que resulta caprichosa o injustificada ${ }^{37}$. Nuestros jueces conocen bien y aplican regularmente esta definición y el "cartabón de la racionalidad" asociado a ella, tratándose de un método flexible que permite tomar en consideración una serie de elementos propios de los casos de discriminación, tales como la naturaleza de los derechos o intereses involucrados, la gravedad de la vulneración, la importancia de la finalidad perseguida y el contexto ${ }^{38}$. Además se trata de un estándar utilizado en derecho comparado e internacional ${ }^{39}$, en parte dada la naturaleza propia del derecho a la igualdad y la no discriminación. En efecto, virtualmente cualquier acto de autoridad implica imponer una diferencia de trato, y por lo mismo, someter todo acto o decisión de la autoridad a un test complejo y exigente, sería impracticable, además de eventualmente cuestionable bajo los principios de deferencia al legislador

${ }^{34}$ Esto ya fue definido por el Tribunal Constitucional en el fallo sobre el Proyecto de Ley Orgánica Constitucional sobre Votaciones Populares y Escrutinios, rol $\mathrm{N}^{\circ}$ 53-88, doctrina constantemente reiterada en fallos posteriores. Recientemente, véase el fallo sobre el Proyecto de Ley de Presupuestos para el año 2016, rol No 2935-15.

35 McCrudden, Christopher y Prechal, Sacha, cit. (n. 19), pp. 11 y ss.; Michelman, Frank, The Meanings of Legal Equality, en The BlackLetter Journal 3 (1986), Spring, pp. 26-27.

${ }^{36}$ Díaz de VAldés, José Manuel, La Igualdad Constitucional: Múltiple y Compleja, en Revista Chilena de Derecho 42 (2015), 1, pp. 170-171.

37 CEA, José, Derecho Constitucional Chileno (2a edición, Santiago, Ediciones Universidad Católica de Chile, 2012), II, p. 138; Silva, Alejandro, Tratado de Derecho Constitucional (2a edición, Santiago, Editorial Jurídica de Chile, 2006), XI pp. 121-127; FERnÁndeZ, Miguel Ángel, Principio Constitucional de la Igualdad ante la Ley (Santiago, LexisNexis, 2004), pp. 73-82.

${ }^{38}$ Gerards, Janneke, Intensity, cit. (n. 9), pp. 169-181; Díaz de Valdés, José Manuel, La Prohibición de una Discriminación Arbitraria Entre Privados, en Revista de Derecho de la Universidad Católica de Valparaiso 42 (2014), 1, pp. 181-183.

${ }^{39}$ Díaz, Iván, cit. (n. 1), pp. 637-641; Gerards, Janneke, Intensity, cit. (n. 9), pp. 135-183. 
y de separación de funciones. Cabe también señalar que, normalmente, en las alegaciones de discriminación es posible invocar adicionalmente la vulneración de otro derecho. En tales casos, la intervención sobre aquel derecho "adicional" podría llevar al juez a utilizar un test más exigente, como la proporcionalidad ${ }^{40}$. Finalmente, en cuanto a las diversas nociones y estructuras de la racionalidad, nos parece que el fallo del Tribunal Constitucional, rol $\mathrm{N}^{\circ}$ 2935-15, ha constituido un gran avance, al señalar con precisión que dicho test supone una relación - adecuada y directa ${ }^{41}$ - entre tres elementos: "1) la finalidad (...), (2) la diferencia concreta de trato que se establece (...), y (3) el criterio de diferenciación" "22. Se opta así por una estructura tripartita que orienta al juez hacia una noción más demandante del test, ya que exige una relación directa (no una causalidad laxa), entre todos los elementos que considera la racionalidad.

En definitiva, encontramos que si bien es claro que el efecto esencial de las categorías sospechosas es hacer sospechar al juez que se encuentra frente a una discriminación arbitraria, se producen discusiones y confusiones sobre una materia cercana pero diferente, cual es la definición del test que se utilizará para determinar la concurrencia de una discriminación arbitraria. Un cambio o agravación del test no es un efecto esencial, aunque sí una consecuencia posible, de la utilización de las categorías sospechosas.

b) Efectos erróneos, ocasionales o controversiales.- Un primer efecto erróneo en esta materia es la consideración de las categorías sospechosas como clasificaciones prohibidas strictu sensu. Por lo mismo, es necesario afirmar categóricamente que no existe una interdicción absoluta para utilizarlas ${ }^{43}$. Así, por ejemplo, el sexo puede justificar la entrega de un beneficio en razón del embarazo. Del mismo modo, la religión fue utilizada exitosamente en Irlanda del Norte en las políticas de reclutamiento policial para lograr conformar una policía integrada de protestantes y católicos, de forma que ambas comunidades pudiesen confiar en ella ${ }^{44}$. En definitiva, toda categoría

40 Sobre la preferencia del test de racionalidad sobre la proporcionalidad en temas de igualdad, véase DíAz de VAldés, José Manuel, La Gratuidad Discriminatoria, en Fermandois, Arturo y Soto, Sebastián (editores), Sentencias Destacadas 2015 (Santiago, LyD, 2016),) pp. 245-248.

${ }^{41}$ Cons. 42.

${ }^{42}$ Cons. 36.

43 SAdUrSki, Wojciech, cit. (n. 19), pp. 111-124; Arnardóttir, Oddný, cit. (n. 2), pp. 62-63; AtriA, Fernando, cit. (n. 19), pp. 64-67; DíAz, Iván, cit. (n. 1), pp. 644-645; Alvear, Julio y Covarrubias, Ignacio, Hecha la Ley, Hecha la Trampa: Un Análisis de los Errores de la Legislación "Antidiscriminación”, en Actualidad Jurídica 13 (2012), 26, pp. 14-16.

${ }^{44}$ Véase Court of Justice in Northern Ireland, Parsons Application (23/07/2002). 
sospechosa podría utilizarse para diferenciar, pero siempre y cuando el juez llegue al convencimiento pleno de que no se trata de una discriminación arbitraria. En dos palabras, frente a una categoría sospechosa el juez debe hacer precisamente eso, sospechar, y no necesariamente condenar.

Otro efecto que ocasionalmente se le reconoce a las categorías sospechosas es la inversión de la carga de la prueba ${ }^{45}$. A nuestro parecer, esta consecuencia puede presentar una utilidad más aparente que real, dadas las circunstancias concretas de los juicios de discriminación. Lo normal en estos es que la víctima se concentre en acreditar la diferencia de trato que ha sufrido. Sólo eventualmente se aventurará a detallar $-\mathrm{y}$ menos probar- la razón detrás de tal diferencia (ya sea enunciando un factor determinado, como la raza, o identificando la fuente de la discriminación, por ejemplo, la existencia de prejuicios o estereotipos). Por su parte, el acusado de discriminación se concentrará, ya sea en negar la diferencia de trato en cuestión, o si la reconoce, en acreditar la razonabilidad de la diferencia establecida. En otras palabras, más allá de la discusión acerca de si la diferencia de trato existió o no, es el demandado quién normalmente ofrece las razones de la distinción realizada, así como la eventual prueba asociada a ello. En este contexto, "invertir la causa de la prueba" debido a la presencia de una categoría sospechosa, no parece modificar radicalmente la situación descrita ${ }^{46}$.

No obstante lo anterior, en ciertas circunstancias la inversión de la carga de la prueba si podría revestir cierta utilidad. Un buen ejemplo lo constituyen los ordenamientos jurídicos que requieren que ciertos actos discriminatorios, para calificarse como tales, respondan a la intención de discriminar ${ }^{47}$, lo cual impone una carga probatoria difícil para la víctima.

${ }^{45}$ Courtis, Christian, cit. (n. 1), pp. 115-116 y 122; Salvador, María, cit. (n. 11), pp. 37 y 42; DulitzKY, Ariel, cit. (n .8), p. 23; DíAz, Iván, cit. (n. 1), pp. 645; FARÍAS, Javiera, Los efectos procesales de la correción en el ordenamiento jurídico chileno con ocasión de la ley $n^{\circ}$ 20.609, en Ars Boni et Aequi 11 (2014), 1, pp. 85-87 y 9091. Véase también la figura adoptada en el artículo 493 del Código del Trabajo, en relación a los efectos de los indicios en el procedimiento de Tutela Laboral.

46 Contrastar con FARíás, Javiera, cit. (n. 45), pp. 85-94 ; MuÑoz, Fernando, Estándares Conceptuales, cargas procesales y reparación en el litigio antidiscriminación. Análisis critico de la jurisprudencia sobre Ley Zamudio entre 2012 a 2015, en Revista de Derecho de Valdivia 28 (2015), 2, pp. 159-160. Véase también RosalEs, Cecilia, Acción de no discriminación arbitraria, en Silva, María Pía y Hernríquez, Miriam (editores), Acciones protectoras de Derechos Fundamentales (Santiago, LegalPublishing, 2014), pp. 268-275, en relación a la discusión parlamentaria de la Ley $\mathrm{N}^{\circ} 20.609$ de 2012.

47 Strauss, Marcy, cit. (n. 25), pp. 935-1015; Mercat-Bruns, Marie, Discrimination at Work. Comparing European, French and American Law (Oakland, 
Finalmente, se ha señalado que las normas que establecen diferencias sobre la base de clasificaciones sospechosas adolecerían de una presunción de inconstitucionalidad ${ }^{48}$. Esta opción, sin embargo, ha sido expresamente rechazada por al menos parte de nuestra doctrina ${ }^{49}$, y adolece de cierta imprecisión en cuanto a sus consecuencias concretas. En razón de lo anterior, no nos parece que sea una alternativa convincente, salvo que se interprete dicha presunción de una forma muy particular, atribuyéndole efectos similares a lo que se ha propuesto en la sección precedente. En efecto, más allá del sentido preciso de la palabra "presunción" en derecho civil o procesal, la doctrina constitucional ha entendido a la presunción de constitucionalidad como una indicación al juez que examina una ley. Aquel debe considerar a la norma como conforme a la constitución "mientras no exista una fuerte o sólida convicción acerca de los vicios de inconstitucionalidad que lo[a] afecten" 50 , vale decir, la norma analizada se considerará constitucional a menos que "la oposición entre el acto sospechoso y la Carta Fundamental fuera concluyente" 51 . A nuestro juicio, las definiciones anteriores podrían entenderse de forma de exigir al juez un alto grado de convencimiento (se habla de sólida convicción y de juicios concluyentes), el cual debe ser mayor al "estándar", que es precisamente lo que proponemos en la sección precedente. Reconocemos, sin embargo, que esta interpretación de la presunción de inconstitucionalidad es sólo una posibilidad, y de ahí nuestra renuencia a adscribir a tal efecto.

\section{Categorías SOSPeChosas EN LA NORMATIVA CHILENA}

Observamos dos problemas fundamentales en nuestra normativa. En primer lugar, no existe texto constitucional o legal alguno que señale en forma explícita la creación o el reconocimiento de categorías sospechosas. Consecuencialmente, la utilización de estas categorías por parte del juez descansa necesariamente sobre un ejercicio interpretativo de algunas normas que analizaremos a continuación. Esta situación es problemática

University of California Press, 2016), cap. 3 y 4; Weber, Mark, Intent in Disability Discrimination Law: Social Science Insights and Comparisons to Race and Sex Discrimination, en University of Illinois Law Review 2016 (2016), 1, pp. 151-172.

${ }^{48}$ Courtis, Christian, cit. (n. 1), pp. 115-116; Dulitzky, Ariel, cit. (n. 8), p. 23.

49 Fernández, Miguel Ángel, cit. (n. 37), pp. 193-197; Atria, Fernando, cit. (n. 19), pp. 68-69.

${ }_{50}$ ZúNIGA, Francisco, El principio Pro requirente en la setencia del tribunal Constitucional sobre la ley orgánica constitucional del Tribunal Constitucional, en Estudios Constitucionales 7 (2009), 2, p.371.

${ }^{51}$ Zapata, Patricio, Justicia Constitucional (Santiago, Editorial Jurídica de Chile, 2008), p. 243. 
no sólo por la incertidumbre e inconsistencias que puede generar (por ejemplo, un juez puede considerar que la norma en cuestión reconoce a la raza como categoría sospechosa y otro juez puede estimar lo contrario), sino también porque los listados de características que se pueden encontrar en algunos textos normativos parecieran obedecer a una lógica diferente, cual es la prohibición de lo que en nuestra doctrina se denominó "igualdad sociológica" ${ }^{2}$. Aquella mandataba que el derecho otorgara el mismo trato a todos sin distinción de sexo, estirpe, condición o similares. En otras palabras, buscando eliminar privilegios, la igualdad sociológica responde a las ideas de generalidad y "neutralidad" o "ceguera" de la ley, en virtud de las cuales las características personales de los individuos deben ser, como regla general, irrelevantes para el sistema jurídico ${ }^{53}$. Se construye así la idea del individuo abstracto frente a la norma, sin raza, sexo, religión, etc. Se trata, por tanto, de una aplicación de la igualdad constitucional clásica que busca, siguiendo la fórmula aristotélica, tratar igual a los iguales y desigual a los desiguales ${ }^{54}$, sin que las características mencionadas puedan ser consideradas para determinar en cuál de las dos hipótesis -igualdad o desigualdad- nos encontramos.

La noción de categorías sospechosas, por el contrario, obedece a una concepción más reciente de igualdad constitucional, inspirada por un principio anti-casta ${ }^{55}$. Esta procura que el derecho no se abstraiga de la

52 Véase Comisión de Estudios de la Nueva Constitución, sesión 93 de 5 de diciembre de 1974, pp. 297-298. Véase también CEA, José, cit. (n. 37), p.130; FernÁNDEz, Miguel Ángel, cit. (n. 37), p. 130; Bulnes, Luz, La Igualdad ante la Ley y la Evolución de la Jurisprudencia del Tribunal Constitucional, en AsOCIACIÓN CHILENA de Derecho Constitucional, Temas Actuales de Derecho Constitucional (Santiago, Editorial Jurídica de Chile, 2009), p. 17.

53 Culp, Jerome, Color Blind Remedies And The Intersectionality Of Opresion: Policy Arguments Masquerading As Moral Claims, en New York University Law Review 69 (1994) pp. 166; Green, Philip, Equality and Democracy (New York, New Press, 1998), p. 126; Loury, Glenn, Why Should We Care About Group Inequality?, en Social Philosophy and Policy 5 (1987), 1, pp. 253-259. Contrastar con PosT, Robert, Prejudicial Appearances: The Logic of American Antidiscrimination Law, en California Law Review 88 (2000), 1, pp. 1-40; PéreZ, Antonio, Dimensiones de la Igualdad (Madrid, Dykinson, 2007), p. 22. Véase también Ferrajoli, Luigi, Derechos y Garantías. La ley del más débil (7a edición, Madrid, Trotta, 2010), p. 75.

${ }^{54}$ Aristóteles, Ética a Nicómaco (traducción de Salvador Rus, Madrid, Tecnos, 2009), Libro V.

55 Díaz de Valdés, José Manuel, La prohibición, cit. (n. 38), p. 156. Véase también Sunstein, Cass, cit. (n. 23), pp. 2428 y ss.; Fiss, Owen, Groups and the Equal Protection Clause, en Philosophy and Public Affairs 5 (1976), 2, pp. 147-156; Michelman, Frank, cit. (n. 35), pp. 27-28; Peters, Anne, Women, quotas and constitutions : a comparative study of affirmative action for women under American, 
realidad, sino que reconozca en aquella la existencia de ciertos grupos desaventajados (afectados en su dignidad, históricamente perjudicados, disminuidos en sus oportunidades, víctimas de una sistemática asimetría de poder, etc.), y que se les otorgue una protección especial. No se trata, por tanto, de fomentar la "neutralidad" del derecho. A la inversa, se busca utilizar el derecho "no neutralmente" para proteger en forma especial a los miembros de ciertos grupos. De ahí la dificultad de interpretar como categorías sospechosas listados creados bajo una lógica tan distinta como lo es la igualdad sociológica.

Una segunda dificultad que observamos en nuestro ordenamiento jurídico es la ausencia de determinación, por parte de la norma, de los efectos o consecuencias de la utilización de categorías sospechosas. Como ya examinamos en la sección precedente, esta es una materia altamente controversial, en que existen distintas alternativas posibles, y de ahí la importancia de que sea el legislador quién la defina de forma general y uniforme. Lo contrario implicaría transferir, fundamentalmente a los jueces, la responsabilidad de determinar tales efectos, con las incertidumbres y contradicciones que ello pudiera implicar. Si bien este fenómeno ha sucedido en derecho comparado (Estados Unidos) ${ }^{56}$, se trata de un proceso de difícil desarrollo en un país de tradición continental como el nuestro, donde los tribunales de justicia suelen preferir el estricto apego a la ley por sobre el desarrollo creativo de la misma. Más aún si consideramos que algunos de los posibles efectos que se pueden atribuir a las categorías sospechosas dicen relación directa con el debido proceso y la rendición y el peso de la prueba en juicio, materias de estricta competencia legal (artículo $19 \mathrm{~N}^{\circ} 3$ y N 26 de la Constitución).

En definitiva, nos parece que las dificultades antes señaladas son de suficiente entidad como para afirmar que las normas legales nacionales no han recepcionado en propiedad las categorías sospechosas. No obstante lo cual, consideramos que existen ciertos indicios imperfectos que podrían servir de base para el desarrollo de esta institución en nuestro país, fundamentalmente a través de la interpretación jurisprudencial y doctrinal, los cuales revisaremos a continuación.

\section{Constitución Politica de la República}

La Constitución no reconoce expresamente categorías sospechosas ni utiliza esta nomenclatura o alguna similar. Tampoco establece una lista

German, EC and international law (London, Kluwer Law International, 1999), pp. 79-81.

${ }^{56}$ Gerards, Janneke, Intensity, cit. (n. 9), pp. 140-149. 
de clasificaciones o factores que pudiera servir de fundamento al posterior desarrollo de esta institución ${ }^{57}$, y mucho menos consagra el efecto que su utilización tendría en el control de la norma o acto que las incluya.

No obstante lo anterior, algunos de los pasajes de la Constitución proveen cierta base para la construcción jurisprudencial o doctrinal de categorías sospechosas. De entre ellas, nos parece que la más defendible sería el sexo. En efecto, el artículo $19 \mathrm{~N}^{\circ} 2$ establece que hombres y mujeres son iguales ante la ley, frase introducida mediante reforma constitucional del año $1999^{58}$. Es así como la Constitución se preocupa de repetir la regla general de la igualdad ante la ley (primera frase del mismo numeral) en su iteración particular con el sexo. Nos parece que una interpretación útil (no meramente reiterativa del contenido general del numeral en comento) y finalista (protectora de los derechos fundamentales y en particular de la igualdad ante la ley) del texto señalado indicaría que, si bien la igualdad de todas las personas y grupos es importante, el constituyente sería particularmente sensible hacia la igualdad de los sexos. Por lo mismo, su mandato de tratamiento igualitario sería especialmente intenso en este caso, y desviaciones al mismo deberían ser aún más excepcionales ${ }^{59}$. El texto señalado, por tanto, podría eventualmente operar como una categoría sospechosa.

Es importante destacar que el sexo cumple con virtualmente todos los criterios normalmente utilizados para seleccionar una categoría sospechosa: es esencial para la determinación de la propia identidad; su mal uso puede impactar directa y severamente a la dignidad de la persona; busca proteger un grupo tradicional, histórica y sistemáticamente discriminado; la discriminación sexual afecta concretamente la calidad de vida de las mujeres y sus oportunidades en múltiples formas, y es un factor inmutable (salvo casos muy excepcionales).

Ahora bien, el texto constitucional -en consonancia con la historia fidedigna de su establecimiento- se refiere sólo a "hombres y mujeres", por tanto el carácter de categoría sospechosa -excepción que, en cuanto tal, requiere una interpretación estricta- sólo se referiría al sexo en clave

${ }^{57} \mathrm{Al}$ redactar el artículo $19 \mathrm{~N}^{\circ}$ 2, sobre igualdad antela ley, la Comisión de Estudios de la Nueva Constitución desechó utilizar listados de características "sociológicas", en razón de la sobriedad del texto constitucional, ya que se consideraban "cubiertas" por la garantía general de igualdad para todos los habitantes. Sesión 94, de 31 de octubre de 1974.

${ }^{58}$ Ley $\mathrm{N}^{\circ} 19.611$ de 1999 . Su historia fidedigna señala que su finalidad era "explicitar la igualdad jurídica entre hombres y mujeres" (Mensaje, p. 4), así como ser una "concreción del derecho fundamental de la igualdad ante la ley" (Mensaje, p.6). No hay registro de una voluntad de establecer el sexo como categoría sospechosa. Véase FernándeZ, Miguel Ángel, cit. (n. 37), pp. 152-188.

59 Fernández, Miguel Ángel, cit. (n. 37), pp. 193-194. 
binaria $^{60}$. No se aplicaría, por tanto, a otras identidades sexuales, o a la orientación sexual.

\section{Legislación}

La legislación chilena no ha consagrado expresamente categorías sospechosas, no obstante lo cual, existen ciertos antecedentes que podrían considerarse como un reconocimiento germinal. El caso más icónico es el de la Ley N²0.609 que Establece Medidas contra la Discriminación (la "Ley Zamudio"). Dicha norma dispone en su artículo $2^{\circ}$ lo siguiente: "Definición de discriminación arbitraria. Para los efectos de esta ley, se entiende por discriminación arbitraria toda distinción, exclusión o restricción que carezca de justificación razonable, efectuada por agentes del Estado o particulares, y que cause privación, perturbación o amenaza en el ejercicio legitimo de los derechos fundamentales establecidos en la Constitución Política de la República o en los tratados internacionales sobre derechos humanos ratificados por Chile y que se encuentren vigentes, en particular cuando se funden en motivos tales como la raza o etnia, la nacionalidad, la situación socioeconómica, el idioma, la ideología u opinión politica, la religión o creencia, la sindicación o participación en organizaciones gremiales o la falta de ellas, el sexo, la orientación sexual, la identidad de género, el estado civil, la edad, la filiación, la apariencia personal y la enfermedad o discapacidad".

El texto antes citado es severamente deficiente debido a la presencia de numerosos errores y confusiones ${ }^{61}$. No sólo se omite hablar expresamente de categorías sospechosas, prohibidas, especiales, etc. (como sí se hizo durante la historia fidedigna de esta ley $)^{62}$, sino que las características o rasgos listados parecieran constituir meras ilustraciones de discriminaciones arbitrarias (dice en particular), sin ninguna gravedad especial ${ }^{63}$. Peor aún, ni en este artículo ni en ninguna parte de la Ley Zamudio se consagran las consecuencias de la utilización de estas calificaciones ${ }^{64}$. Y para colmo, los incisos siguientes al transcrito limitan expresamente los efectos de emplear tales categorías para discriminar, señalando que tales distinciones

${ }^{60}$ Fernández, Miguel Ángel, cit. (n. 37), pp. 187.

${ }^{61}$ Díaz de Valdés, José Manuel, ¿Es la Ley Zamudio Verdaderamente una Ley General Antidiscriminación?, en Actualidad Jurídica 14 (2013), 28, pp. 280- 283.

${ }^{62}$ Historia de la Ley $\mathrm{N}^{\circ} 20.609$ de 2012, pp. 319, 677, 720, 721, 800, 859, 879 , etc.

${ }^{63}$ Véase las diversas posibilidades interpretativas de esta expresión en Díaz, Iván (n. 1), pp. 649-652.

${ }^{64}$ Sobre la historia fidedigna de la Ley Zamudio en relación a la prueba, y su tangencial relación con las categorías sospechosas, véase Rosales, Cecilia, cit. (n. 46), pp. 268-275. 
serán razonables si se justifican "en el ejercicio legitimo de otro derecho fundamental" (artículo $2^{\circ}$ inciso $3^{\circ}$ ), y que "no podrán invocarse, en ningún caso, para justificar, validar o exculpar situaciones o conductas contrarias a las leyes o al orden público" (artículo $2^{\circ}$ inciso $2^{\circ}$ ). En términos simples, la Ley Zamudio pareciera establecer que el derecho a no ser discriminado, aun cuando se utilice el listado de características antes trascrito, cede frente a cualquier otro derecho $0^{65}$ y frente a cualquier otra ley o al orden público ${ }^{66}$.

En razón de todo lo anterior, el texto de la Ley Zamudio no alcanza para dar por establecidas o reconocidas en él a las categorías sospechosas. Aun así, hay alguna jurisprudencia y doctrina que ha querido ver la consagración de estas categorías en la norma en cuestión ${ }^{67}$. Al respecto, existe la posibilidad que dicha interpretación judicial y doctrinal, en la medida que se torne en persistente, termine por configurar lo que el legislador no hizo

Otra situación legislativa que podría servir de indicio a la eventual consagración de las clasificaciones sospechosas, es la que presenta el artículo $2^{\circ}$ del Código del Trabajo ${ }^{68}$ : "Los actos de discriminación son las distinciones, exclusiones o preferencias basadas en motivos de raza, color, sexo, edad, estado civil, sindicación, religión, opinión política, nacionalidad, ascendencia nacional u origen social, que tengan por objeto anular o alterar la igualdad de oportunidades o de trato en el empleo y la ocupación" ${ }^{69}$.

Como se puede apreciar, el texto transcrito no señala que las clasificaciones enumeradas constituyan categorías sospechosas, ni tampoco establece

${ }^{65}$ Confróntese con Rosales, Cecilia, cit. (n. 46), p. 282; Henríquez, Miriam y NúŃEZ, José Ignacio, Ley Zamudio: ¿Ponderación o subsunción? comentario a la sentencia rol $n^{\circ}$ 1009-2014 de la Corte de Apelaciones de Concepción, en Revista de Derecho - Escuela de Postgrado (Universidad de Chile) (2014), 6, pp. 242-244.

${ }^{66}$ Estas limitaciones son reales y se aplican. Véase, por ejemplo, la sentencia del Tribunal Constitucional sobre el artículo 54 de la Ley de Matrimonio Civil, rol $N^{\circ}$ 2435-13, en particular el considerando 19.

${ }^{67}$ Véase Tercer Juzgado de Letras de La Serena, rol C-5058-2015; Vigésimo Sexto Juzgado Civil de Santiago, rol C-7698-2014, y en cierto sentido Juzgado de Letras de Colina, rol C-1165-2015. Véase también Muñoz, Fernando, No a "Separados pero Iguales" en Chile: un Análisis del Derecho Antidiscriminación Chileno a partir de su Primera Sentencia, en Estudios Constitucionales 11 (2013), 2, p. 202; FARÍAS, Javiera, cit. (n. 45), pp. 80-81; VIAL, Tomás, La nueva ley antidiscriminacion: propuestas para avanzar en su perfeccionamiento, en Anuario de Derechos Humanos (2013), 9, pp. 187-188; MuÑoz, Fernando, Estándares, cit. (n. 46), pp. 154-158; Alvear, Julio y Covarrubias, Ignacio, cit. (n. 43), pp. 14-16 y 21-26.

${ }^{68}$ Véase también el artículo 17 de la Ley $\mathrm{N}^{\circ} 18.834$ de 1989.

${ }^{69}$ Ley $\mathrm{N}^{\circ} 18.620$ de 1987. Nótese que el Proyecto de Reforma Laboral boletín $\mathrm{N}^{\circ}$ 9835-13, agrega al listado anterior la "situación socioeconómica, idioma, creencias, participación en organizaciones gremiales, orientación sexual, identidad de género, filiación, apariencia personal, enfermedad o discapacidad”. 
la consecuencia de su utilización. Asimismo, llama la atención la deficiente redacción de la norma, ya que su tenor literal pareciera indicar que sólo habría discriminación si la distinción se fundamenta en el listado de factores que se enumeran. El problema no sólo se produce porque ninguna lista de este tipo puede aspirar a ser exhaustiva (dificultad que puede atenuarse mediante la extensión vía interpretación judicial $)^{70}$, sino también porque existen muchas discriminaciones que no se fundan en categorías "grupales", sospechosas o no. En definitiva, el listado en cuestión pareciera responder al ya comentado concepto de igualdad sociológica ${ }^{71}$, que como señalamos, dista mucho de la noción de categorías sospechosas ${ }^{72}$.

\section{ANÁLISIS DE LA JURISPRUDENCIA CONSTITUCIONAL}

No habiéndose identificado jurisprudencia relevante de la Corte Suprema sobre categorías sospechosas ${ }^{73}$, esta sección se refiere exclusivamente al Tribunal Constitucional. En efecto, se analizaron todas sus sentencias dictadas desde abril de 1981 hasta noviembre de 2017, incluyendo votos de minoría y prevenciones, que se hubiesen referido al artículo $19 \mathrm{~N}^{\circ} 2$ de la Constitución (igualdad en/ante la ley), así como al artículo $1^{\circ}$ inciso final (igualdad de oportunidades). Cabe destacar que se ha privilegiado la retórica utilizada por las sentencias, sin perjuicio de la consideración de ciertos elementos contextuales de cada caso.

\section{Conceptualización}

En términos generales, no existe mayor conceptualización del tópico en estudio. Sí se aprecia cierta confusión ${ }^{74}$ y referencias que parecieran aludir más bien a la antigua noción de igualdad sociológica ${ }^{75}$. No obstan-

${ }^{70}$ La no exhaustividad de esta lista pareciera ser una materia pacífica. Véase, e.g., UGarte, José Luis, El derecho a la no discriminación en el trabajo (Santiago, LegalPublishing, 2013), pp. 21-24.

${ }^{71}$ Según la historia fidedigna de esta norma (Ley N 18.620 (Código del Trabajo) de 1987), el origen de esta disposición fue el artículo $1^{\circ}$ del Convenio 111 de la OIT, cuestión que se reitera en la historia fidedigna de la Ley $\mathrm{N}^{\circ} 19.759$ de 2001, en el cual no se hace mención alguna a la noción de categoría sospechosa.

${ }^{72}$ Existen doctrina laboral (UGARTE, José Luis, cit. (n. 70), pp. 20-27) así como jurisprudencia en contrario (véase Primer Juzgado de Letras del Trabajo de Santiago, rol T-38-2010).

${ }^{73}$ Se revisaron todas las sentencias recaídas sobre recursos de protección referidos al artículo $19 \mathrm{~N}^{\circ} 2$ de la Constitución Política de la República, dictadas entre enero de 2011 y diciembre de 2015.

${ }^{74}$ Tribunal Constitucional, prevención, rol No 2787-15, cons. 8.

${ }^{75}$ E.g., Tribunal Constitucional, rol No 811-08, cons. 19; rol No 2456-13, cons. 9. 
te lo anterior, existen ciertos votos de minoría relevantes. Uno de ellos, adoptando una perspectiva funcional, señaló que las categorías sospechosas tendrían por objetivo la "protección de un grupo o colectividad cuyo status o condición se busca igualar en la sociedad, pues se trata de grupos minoritarios especialmente vulnerables" 76 , lenguaje que denota una lógica anti-casta y que pareciera acercarse a la experiencia norteamericana. Otro voto de minoría, reiterado posteriormente, intenta identificar las causales o justificaciones de estas clasificaciones: "Hay diferenciación sospechosa cuando se cierne sobre un grupo que históricamente ha tenido una penetrante discriminación en contra de su clase, cuando ha sido estigmatizado por efecto de la clasificación, cuando la clasificación está basada en un estatus inmutable o en condiciones que la persona no puede controlar o cuando la discriminación construye un efecto que aisla a los individuos sujetos de discriminación generando un debilitamiento de sus garantías en la protección de sus derechos civiles y fundamentales" ${ }^{\prime \prime}$. Entendiendo que se trata de justificaciones no copulativas, se observa en ellas un énfasis en la utilización que se ha hecho de tales factores, por sobre sus características propias. Ello, a su vez, destaca la importancia que tiene cada contexto particular -histórico y social- en la configuración de estas categorías.

\section{Factores que constituirian categorias sospechosas}

La primera característica personal expresamente tratada de esta forma fue la nacionalidad (distinción extranjero-chileno), la que fue calificada como sospechosa, en línea de principio $^{78}$. Este fallo también afirmó que el legislador (vía Ley Zamudio) habría establecido la raza como categoría sospechosa, apreciación que nos parece errada según lo antes expuesto. Adicionalmente, la misma sentencia pareciera agregar al idioma entre las características en comento.

Posteriormente, encontramos dos sentencias del Tribunal que, luego de reconocer existencia de criterios sospechosos, agregan que: "nuestra Constitución no contiene un listado taxativo de factores que predeterminen un ejercicio especialmente cauteloso a la hora de hacer diferencias o distinciones en decisiones públicas o en leyes propiamente tales o en reglas de trato"79. En virtud de lo anterior, el Tribunal invoca al artículo $5^{\circ}$ de la Constitución

76 Tribunal Constitucional, voto de minoría, rol N²231-12, cons. 4.

77 Tribunal Constitucional, votos de minoría, roles $\mathrm{N}^{\circ} 2435-13$ y No 2681-14, cons. 14 y 21 , respectivamente.

${ }^{78}$ Tribunal Constitucional, rol No 2273-12, cons. 30. Véase también cons. 32 y 33.

79 Tribunal Constitucional, roles $\mathrm{N}^{\circ} 2777-15$ y $\mathrm{N}^{\circ} 2702$, cons. 15 y 8 , respectivamente. 
para recurrir a los artículos $2^{\circ}$ y 26 del Pacto Internacional de Derechos Civiles y Políticos (el "PIDCP”), así como a los artículos $1^{\circ}$ y $24^{\circ}$ de la Convención Americana de Derechos Humanos (la "Convención”). Si bien la normativa internacional no es el objeto de este artículo, quisiéramos mencionar brevemente que las normas citadas, si bien establecen listados de rasgos o características personales, no señalan expresamente que se trate de categorías sospechosas, o cual sería la consecuencia de utilizarlas. En nuestra opinión, los tratados mencionados hacen referencia a un marco conceptual más antiguo, cual es la prohibición de la "discriminación sociológica", explicada previamente ${ }^{80}$. Cabe reconocer, sin embargo, que existen algunos pronunciamientos de la Corte Interamericana de Derechos Humanos que parecieran atribuir el estatus de categorías sospechosas a los criterios o factores recogidos en el artículo 1.1 de la Convención. El problema es que el marco conceptual utilizado es incompleto, y las consecuencias atribuidas a su uso son contradictorias. Por lo mismo, es probable que la Corte esté utilizando de manera impropia el concepto de categorías sospechosas ${ }^{81}$.

En forma más reciente, un fallo del Tribunal bosqueja una suerte de listado de categorías sospechosas de consagración constitucional, las que incluirían el género (artículo $19 \mathrm{~N}^{\circ} 1$ ), la raza (artículo $19 \mathrm{~N}^{\circ} 2$ ), la posición económica o de poder social o político (artículo $19 \mathrm{~N}^{\circ} 2$ ), la nacionalidad (artículo 14, 19 y $19 \mathrm{~N}^{\circ} 16$ ) y el mérito (artículo 1, $19 \mathrm{~N}^{\circ} 17$ y 38) - según la sentencia, todos estos factores habrían sido previamente reconocidos por el Tribunal- "sin descartar que no exista controversia sobre otras fuentes de diferenciación (orientación sexual, filiación, discapacidad, etc.)" 82 . Adicionalmente, se invocan instrumentos de derecho internacional como fuente última de tales categorías, parte de cuyo contenido habría sido recibido por el derecho laboral y la Ley Zamudio ${ }^{83}$. Debe reconocerse el esfuerzo sistematizador de esta sentencia, si bien la inclusión del mérito evidencia una confusión conceptual importante.

Existen también algunos votos de minoría y prevenciones relevantes, particularmente en relación al sexo y la orientación sexual. El primero es del año 2011, y señala que el sexo sería "una categoría paradigmáticamente sospechosa”, reconocida como tal por la misma Constitución en su artículo

${ }^{80}$ BAYEFSKY, Anne, cit. (n. 5), pp. 5-8.

${ }^{81}$ Véase Corte Interamericana de Derechos Humanos, Atala Riffo e hijas vs. Chile (24/02/2012), $\mathrm{N}^{\circ}$ s 83-93 y 124-125; Norín Catriman y Otros vs. Chile, (29/5/2914), N 196-206 .Véase también DulitzKY, Ariel, cit. (n. 8), en particular sus conclusiones (pp. 31-32).

${ }^{82}$ Tribunal Constitucional, rol $\mathrm{N}^{\circ} 2838$, cons. 20.

${ }^{83}$ Tribunal Constitucional, rol No 2838 , cons. 19 y 20. 
$19 \mathrm{~N}^{\circ}$ 2. Cita además el artículo 2.1 del PIDCP, el cual se refiere al goce de derechos sin distinción alguna de raza, color, sexo, etc., por cuanto estaría "identificando asi una serie de criterios sospechosos de discriminación, entre los

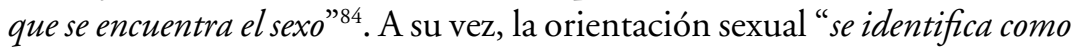
categoría sospechosa en diversas convenciones internacionales sobre derechos humanos vigentes en Chile" 85 . Posteriormente, en una prevención se señaló nuevamente que el sexo y la orientación sexual "corresponden a las denominadas categorías sospechosas de discriminación"86. También se identificó como criterios sospechosos a las características listadas en el artículo 2.1 del PIDCP. Curiosamente, se agregó: "Como lo ha sostenido este Tribunal, el empleo de estos criterios sospechosos puede transformarse en una categoría contraria a la igualdad ante la ley cuando manifieste el "propósito de hostilidad contra determinada persona o grupo de personas" (STC Rol 986/2008; STC Rol 1414/2010)". Esta reflexión es extraña en el contexto de nuestro derecho doméstico: ¿constituye la hostilidad un requisito adicional para que se trate de una categoría sospechosa? ¿O la presencia de hostilidad convierte a tal categoría en inconciliable con la igualdad constitucional, y por tanto, derechamente prohibida? Tal vez se quiso decir que una categoría sospechosa sólo se considera tal cuando afecta grupos desaventajados (por ejemplo, a los homosexuales y no a los heterosexuales). En cualquier caso, la formulación elegida no es la más feliz, ya que la discriminación de tales grupos no siempre surge de sentimientos hostiles (puede tratarse de estereotipos, preferencias, paternalismo, etc. $)^{87}$. Adicionalmente, la hostilidad también puede dirigirse contra grupos privilegiados, o contra individuos sin adscripción a un grupo desaventajado, situaciones que se alejan de la formulación propia de las categorías sospechosas.

Posteriormente, destaca el voto de minoría en un caso referido a la preferencia materna en la tuición de los hijos, el cual afirma explícitamente que el sexo es un criterio sospechoso ${ }^{88}$. En la misma línea, existe un voto de minoría que enumera como categorías sospechosas al sexo, la raza, las creencias religiosas, las opiniones políticas y la orientación sexual, entre otras $^{89}$. Algo similar ocurre en otros votos de minoría que hablan de motivos sospechosos, pareciendo referirse al sexo y la filiación, los que a su vez estarían comprendidos en diferencias que afectan a la maternidad ${ }^{90}$.

\footnotetext{
${ }^{84}$ Tribunal Constitucional, voto de minoría, rol N $1683-10$, cons. 18 y 39.

85 Tribunal Constitucional, voto de minoría, rol No $1683-10$, cons. 40 y 41.

${ }^{86}$ Tribunal Constitucional, prevención, rol No 1881-10, cons. 27.

${ }^{87}$ Díaz de Valdés, José Manuel, La prohibición, cit. (n. 38), pp. 179- 181.

${ }^{88}$ Tribunal Constitucional, voto de minoría, rol N² 2306-12, cons. 25.

89 Tribunal Constitucional, voto de minoría, rol No 2231-12, cons. 5.

90 Tribunal Constitucional, votos de minoría, roles $\mathrm{N}^{\circ} 2250-12$, cons. 22; $\mathrm{N}^{\circ}$
} 
Más recientemente, dos votos de minoría se desvían algo de lo antes señalado al declarar que: "Es evidente que las clasificaciones basadas en sexo en cuanto género no son necesariamente sospechosas y, por ende, no implican per se la adopción de un estricto escrutinio de juzgamiento, salvo cuando la discriminación refleja un estereotipo arcaico que manifiesta significativas diferencias entre los sexos." 91 . La redacción es algo confusa, pero pareciera afirmarse que el género no sería una categoría sospechosa (¡el sexo sí?), salvo en ciertos supuestos. Estos mismos votos de minoría parecieran asumir las características listadas en el artículo 26 del PIDCP constituirían categorías sospechosas. Agregan estos votos que la Corte Interamericana de Derechos Humanos habría considerado al sexo como una categoría sospechosa en el caso Morales de Sierra contra Guatemala (esto es un error, ya que se trata de una opinión de la Comisión Interamericana de Derechos Humanos ${ }^{92}$, y no de una sentencia de la Corte). Algo similar ocurriría con la orientación sexual y la identidad de género, para lo cual se cita el caso Atala Riffo contra Chile ${ }^{93}$.

Finalmente, un "voto de mayoría"94 del fallo rol N²650 de 2014, pareciera identificar como categorías sospechosas (no expresamente, pero sí indirectamente al atribuirle ciertos efectos) al sexo, la raza, la nacionalidad y la filiación.

En definitiva, no existe aún en la jurisprudencia del Tribunal un listado preciso de las características que podrían constituir categorías sospechosas. La más consolidada sería el sexo, y en menor medida, la raza y la nacionalidad. Otros factores gozarían de menos consolidación, tales como la filiación, la edad y la orientación sexual.

\section{Efectos de las categorias sospechosas}

En esta materia, la jurisprudencia del Tribunal pareciera ser particularmente confusa. Es así como en un voto de minoría se afirmó tajantemente que: "es un lugar común sostener que toda discriminación fundada en raza, sexo o clase es contraria a derecho" ${ }^{\prime 5}$. Afortunadamente se trata de una decla-

2357-12, cons. 22; $\mathrm{N}^{\circ} 2482-13$, cons. 22; N² 2503, cons. 22.

${ }_{91}$ Tribunal Constitucional, votos de minoría, roles $\mathrm{N}^{\circ} 2435-13$ y № 2681-14, cons. 13 y 20 , respectivamente.

${ }^{92}$ Comisión Interamericana de Derechos Humanos, Informe $\mathrm{N}^{\circ}$ 04/01 Morales de Sierra vs. Guatemala (19/1/1998). Véase en particular el Nº 36.

${ }^{3}$ Corte Interamericana de Derechos Humanos, Atala Riffo e hijas vs. Chile (24/02/2012), cons. 91.

${ }_{94}$ Tribunal Constitucional, rol No 2650-14. Existió empate de votos, por lo cual se rechazó el recurso, y de ahí que denominemos "voto de mayoría" al de los ministros que votaron en contra del recurso.

95 Tribunal Constitucional, voto de minoría, rol Nº 1243-08, cons. 18. 
ración obiter, ya que refleja una simplificación equivocada, la que además queda desmentida por una serie de pronunciamientos del Tribunal, donde se someten tales categorías al examen de razonabilidad ${ }^{96}$.

Posteriormente, existen dos fallos en que, si bien no se mencionó el término "categoría sospechosa", se afirmó que: "la diferenciación por el criterio de edad no es, en si misma, jurídicamente reprochable", proveyéndose una serie de ejemplos en los que el ordenamiento jurídico la utiliza ${ }^{97}$. Se agregó que tales diferencias " no deben afectar al más débil", lo que pareciera ser un indicio de la noción de la igualdad constitucional centrada en una lógica "anti-casta". Consecuentemente, aparece implícita la posibilidad de aplicar un control más rigoroso en caso de afectarse el grupo desaventajado.

En 2011, un voto de minoría declaró que las categorías sospechosas "obligan a un análisis más riguroso y exigente del principio de igualdad, pues su presencia invierte la presunción de constitucionalidad de que en virtud del principio de deferencia al legislador goza todo precepto legal, ya que pueden afectar a grupos minoritarios especialmente vulnerables a un trato discriminatorio (...) el sexo y la orientación sexual (...) constituyen "categorías sospechosas" que invierten la presunción de constitucionalidad de todo precepto legal y exigen realizar un test estricto de proporcionalidad al analizar la afectación de la igualdad ante la ley" ${ }^{\text {"98 }}$. Como ya señalamos, no nos parece lo más conveniente plantear la cuestión en términos de presunción de inconstitucionalidad. El término "categoría sospechosa" responde a la idea de sospecha: hay un llamado al juez a desconfiar, a exigir razones más convincentes para justificar el uso de tal categoría. Ello no es en estricto rigor una presunción, medio de prueba que consiste en "presumirse el hecho que se deduce de ciertos antecedentes o circunstancias conocidas" (artículo 47 del Código Civil). Si bien existen similitudes entre el trato que en derecho comparado se otorga a las categorías sospechosas y a una presunción simplemente legal en Chile, adaptar esta última nomenclatura podría, por una parte, reducir la noción de categoría sospechosa a un ámbito netamente probatorio, y por otra, rigidizar un concepto de suyo flexible. Todo ello sin considerar los problemas que pudiera acarrear para la relación inter-órganos una verdadera "presunción de inconstitucionalidad" de los actos del legislador o de la administración. A mayor abundamiento, no se entiende qué rol tendría, frente a una presunción de inconstitucionalidad, la exigencia que hace el voto de minoría de un test más severo para evaluar la desigualdad (¿serían

${ }^{96}$ Por ejemplo, véase el famoso fallo "Isapres", Tribunal Constitucional, rol $\mathrm{N}^{\circ}$ 1710-10, cons. 145.

${ }_{97}$ Tribunal Constitucional, roles $\mathrm{N}^{\circ} 1273-08$ y $\mathrm{N}^{\circ} 1348-09$, principalmente en los cons. 69 y 55, respectivamente.

${ }_{98}$ Tribunal Constitucional, voto de minoría, rol N $1683-10$, cons. 18, 36 y 37. 
acumulativos? ¿Debería el juez presumir la inconstitucionalidad y además ser muy exigente cuando le intenten refutar la presunción?).

Adicionalmente, encontramos en este voto de minoría un nuevo indicio de la noción de igualdad "anti-casta", ya que se justifica la presunción de inconstitucionalidad en el daño a los grupos desaventajados. Podría, por tanto, afirmarse que el uso de una categoría sospechosa para beneficiar tales grupos no quedaría sujeta a la misma presunción.

Algunas de las ideas anteriores se reiteran en una prevención posterior, donde se afirma que el uso de categorías sospechosas: "invierte la presunción de constitucionalidad de que goza el legislador en virtud del principio de deferencia, ya que pueden afectar a personas integrantes de colectivos minoritarios más vulnerables en razón de una trayectoria de discriminación. Lo anterior exige realizar un examen más estricto de razonabilidad"'99.

Posteriormente, existen cuatro votos de minoría de que parecieran afirmar, mediante una redacción algo confusa, que el uso de categorías sospechosas (o al menos de algunas de ellas), haría que "la carga argumentativa de la distinción en este ámbito debe ser especialmente contundente $y$ convincente" ${ }^{100}$. En la misma línea, el Tribunal dictó una sentencia en el año 2013 que, si bien no se refiere explícitamente a la noción de categoría sospechosa, señala que cuando se usa el sexo para establecer una diferencia de trato "la razonabilidad de la justificación debe ser especialmente fuerte" ${ }^{101}$. Esta misma consideración fue luego citada en un fallo de minoría, el que agregó que "la diferenciación debe tener una relación directa y muy significativa (si no necesaria) para alcanzar la finalidad buscada por la ley", añadiendo que: "La carga de probar la conexión directa, sustancial (y' eventualmente, necesaria) entre la clasificación o distinción legal y la finalidad de la norma recae en el Estado o, al menos, en quien defiende la discriminación "102.

En estos dos últimos fallos, llama la atención que la diferencia de trato impugnada afectaba a los hombres, no a las mujeres, lo que mostraría que la mayor exigencia en la justificación se aplicaría en razón del factor utilizado (sexo), y no del grupo afectado.

Ahora bien, la exigencia de una "excelente justificación” pareciera haberse llevado a un extremo en un voto de minoría que declaró que: "la distinción extranjero-chileno puede realizarse y el texto fundamental no la prohibe. Sin embargo, se trata de una distinción que es sospechosa, en linea de principio, puesto que requiere de una habilitación constitucional previa

99 Tribunal Constitucional, prevención, rol № 1881-10, cons. 27.

100 Tribunal Constitucional, votos de minoría, roles $\mathrm{N}^{\circ} 2250-12$, cons. 22; $\mathrm{N}^{\circ}$ 2357-12, cons. 22; $\mathrm{N}^{\circ}$ 2482-13, cons. 22; $\mathrm{N}^{\circ} 2503$, cons. 22.

101 Tribunal Constitucional, voto de minoría, rol No 2320-12, cons. 15.

${ }^{102}$ rol N²664, considerandos 7 y 8. 
para poder realizarla (...) [y] exige una fuerte argumentación contraria que demuestre la necesidad, justificación y finalidad en un objetivo constitucionalmente legitimo que apodere a la Administración del Estado a realizar una diferencia de trato entre ellos. Esta diferencia puede originar dos modalidades muy diversas de restricciones (...) Las prohibiciones (...) deben tener una habilitación constitucional expresa. En cambio las limitaciones se fundan en la Constitución y, normalmente, en apoderamientos al legislador bajo las reglas propias de la reserva legal y con las restricciones jurídicas que nacen del principio de proporcionalidad y del respecto al contenido esencial de los derechos" ${ }^{103}$.

La primera parte del texto nos lleva a pensar que nos encontraríamos frente a una suerte de categoría sospechosa "agravada", ya que si bien no está completamente prohibida, requiere nada menos que de una autorización constitucional para poder utilizarse. Cabe precisar, sin embargo, que el fallo en cuestión no se está refiriendo a una diferencia de trato cualquiera, sino que a distinciones en la titularidad de derechos. En otras palabras, se estaría afectando el corazón de la igualdad constitucional en cuanto igualdad de derechos ya consagrada en el artículo $1^{\circ}$ de la Constitución, y de ahí puede entenderse la exigencia de habilitación constitucional. Es por ello que la segunda parte del texto transcrito nos sitúa en el contexto de la privación y regulación de derechos constitucionales. Desconocer un derecho constitucional a una persona por el sólo hecho de ser extranjero se considera una privación, y por tanto quedaría sujeta a la exigencia general en tales situaciones, cuál sería la habilitación constitucional expresa. En síntesis, el considerando en cuestión no está señalando que todo uso de una categoría sospechosa requiera dicha habilitación, sino que en este caso sería así porque la diferencia de trato consiste en la privación de un derecho fundamental.

Tiempo después, en 2014, dos votos de minoría señalaron que: "los dilemas que utilizan como criterio de clasificación al sexo como un ejercicio de distinción superior a la mera diferenciación de género, no pueden ser evaluados mediante un test básico de igualdad. Para ellos rige un escrutinio exigente, puesto que se utiliza un criterio que impone un significativo peso sobre grupos protegidos, como es el caso de los homosexuales, sujetos de históricas discriminaciones" ${ }^{104}$. De esta forma, el uso de categorías sospechosas gatillaría un escrutinio estricto por parte del juez.

Luego, destaca una sentencia relativamente reciente del Tribunal que menciona en forma expresa la existencia de criterios sospechosos y ofrece

103 Tribunal Constitucional, voto de minoría, rol Nº 2257-13, cons. 24.

${ }_{104}$ Tribunal Constitucional, votos de minoría, roles $\mathrm{N}^{\circ} 2435-13$ y $\mathrm{N}^{\circ}$ 2681-14, cons. 14 y 21 , respectivamente. 
cierta metodología para el examen de igualdad. Lo primero sería determinar si concurre un "criterio sospechoso en el término de comparación", lo que conduciría a un "ejercicio especialmente cauteloso a la hora de hacer diferencias o distinciones" ${ }^{105}$. Lamentablemente, este último no fue ni descrito ni aplicado por el Tribunal, ya que se consideró que en la especie no concurría un criterio sospechoso (se trataba de distorsiones territoriales en el sistema electoral que afectaban la igualdad del voto).

Finalmente, un "voto de mayoría", si bien no se refirió expresamente a las categorías sospechosas, estableció que la utilización del sexo, la raza, la nacionalidad y filiación política, elevaban "la intensidad del escrutinio relativo a la racionalidad de la justificación" 106.

\section{Evaluación general}

Si bien se aprecia una incipiente utilización de la noción de categorías sospechosas en la jurisprudencia del Tribunal, aquella se produce principalmente en votos de minoría y prevenciones ${ }^{107}$. Reconociendo orientaciones en el derecho internacional, se evidencia un esfuerzo por cimentar estas categorías sobre una base constitucional y legal. Por otra parte, encontramos poca precisión -y en ocasiones confusión- en los fallos estudiados, tanto a nivel conceptual como sobre los efectos de su utilización, si bien existe una clara tendencia a exigir un examen o control más riguroso. Aquellos problemas podrían ser consecuencia de las falencias de los textos normativos aplicables, así como de la persistente influencia de la noción de igualdad sociológica. Adicionalmente, se observan variaciones importantes en relación al factor específico de que se trate, destacando la especial consideración al sexo como posible categoría sospechosa de creación constitucional.

\section{CONCLUSIONES}

a) Las categorías sospechosas son características o rasgos personales que, como regla general, no deben utilizarse para establecer diferencias entre las personas, y que el ordenamiento jurídico ha señalado expresamente como indiciarios de discriminación arbitraria.

b) Su utilización no está prohibida por el derecho, pero se exige al juez alcanzar un alto grado de convencimiento de que no existe discriminación.

\footnotetext{
105 Tribunal Constitucional, rol No 2777-15, cons. 14 y 15 .

106 Tribunal Constitucional, rol No 2650-14, cons. 5. Existió empate de votos, por lo cual se rechazó el recurso, y de ahí que denominemos "voto de mayoría" al de los ministros que votaron en contra del recurso

${ }^{107}$ Coincidiendo con IÑIgueZ, Andrea, cit. (n. 3), pp. 514-515.
} 
Esto no requiere, necesariamente (y tampoco parece conveniente), sustituir el test de racionalidad por otro más exigente, ni tampoco alterar la carga de la prueba o la presunción de constitucionalidad de las normas.

c) Si bien existe alguna doctrina y jurisprudencia que asumen la vigencia de las categorías sospechosas en el ordenamiento jurídico chileno, ni en la Constitución ni en la ley existe un reconocimiento explícito de esta noción, ni tampoco una singularización clara de sus efectos.

d) El TC ha comenzado a utilizar el concepto de categorías sospechosas, principalmente en votos de minoría y prevenciones. No obstante ciertas imprecisiones y confusiones, se aprecia una tendencia a exigir un control más riguroso, así como el surgimiento de un listado tentativo de las mismas en que destaca el sexo.

e) En definitiva, la incorporación de las categorías sospechosas al derecho chileno es aún dudosa, o a lo menos incompleta, denotando falencias y confusiones, tales como la simplista vinculación se las mismas a listados preexistentes de características personales, los cuales responden a nociones más antiguas de igualdad.

$f)$ Es posible que una adecuada aplicación jurisdiccional de las diversas nociones de igualdad constitucional haga innecesaria la utilización de categorías sospechosas. Sin embargo, nos parece que el escenario más conveniente, particularmente desde la perspectiva de la seguridad jurídica y la coherencia de nuestro sistema de fuentes, sería una consagración normativa expresa de algunas categorías sospechosas, que defina claramente los efectos de su utilización, y que reconozca el insustituible rol del juez en la determinación de la legitimidad de su utilización.

\section{BIBLIOGRAFÍA}

Alvear, Julio y Covarrubias, Ignacio, Hecha la Ley, Hecha la Trampa: Un Análisis de los Errores de la Legislación “Antidiscriminación”, en Actualidad Jurídica 13 (2012), 26. Aristóteles, Ética a Nicómaco (traducción de Salvador Rus, Madrid, Tecnos, 2009). ArnardótTir, Oddný, Multidimensional equality from within, en SHIEK, Dagmar y CHEge, Victoria (editores), European Union Non-discrimination law (Nueva York, Routledge-Cavendish, 2009).

Atria, Fernando, Los Peligros de la Constitución. La Idea de Igualdad en la Jurisdicción Nacional (Santiago, Escuela de Derecho Universidad Diego Portales, 1997).

BAKER, Aaron, Proportional, not strict, scrutiny: Against a U.S. "Suspect Classifications" model under Article 14 ECHR in the U.K., en The American Journal of Comparative Law 56 (2008), 4.

BAYEFSKY, Anne, El principio de igualdad o no discriminación en el derecho internacional, en Human Rights Law Journal 11 (1990), 1-2.

BESSON, Samantha, Evolutions in non-discrimination law within the ECHR and the ESC systems: It takes two to tango in the council of Europe, en The American Journal of Comparative Law 60 (2012), 1. 
Brest, Paul, In Defense of the Antidiscrimination Principle, en Harvard Law Review 90 (1976), 1.

Bulnes, Luz, La Igualdad ante la Ley y la Evolución de la Jurisprudencia del Tribunal Constitucional, en Asociación Chilena de Derecho Constitucional, Temas Actuales de Derecho Constitucional (Santiago, Editorial Jurídica de Chile, 2009).

CEA, José, Derecho Constitucional Chileno (2a edición, Santiago, Ediciones Universidad Católica de Chile, 2012), II.

Courtis, Christian, Dimensiones Conceptuales de la Protección Legal contra la Discriminación, en Revista Derecho del Estado (2010) 24.

Culp, Jerome, Color Blind Remedies And The Intersectionality Of Oppression: Policy Arguments Masquerading as Moral Claims, en New York University Law Review 69 (1994).

Díaz, Iván, Ley chilena contra la discriminación. Una evaluación desde los derechos internacional y constitucional, en Revista Chilena de Derecho 40 (2013), 2.

DíAZ de VAldÉs, José Manuel, ¿Es la Ley Zamudio Verdaderamente una Ley General Antidiscriminación?, en Actualidad Jurídica 14 (2013), 28.

Díaz de Valdés, José Manuel, La Gratuidad Discriminatoria, en Fermandois, Arturo y Soтo, Sebastián (editores), Sentencias Destacadas 2015 (Santiago, LyD, 2016).

Díaz de Valdés, José Manuel, La Igualdad Constitucional: Múltiple y Compleja, en Revista Chilena de Derecho 42 (2015), 1.

Díaz de Valdés, José Manuel, La Prohibición de una Discriminación Arbitraria Entre Privados, en Revista de Derecho de la Universidad Católica de Valparaiso 42 (2014), 1.

Dulitzky, Ariel, El principio de igualdad y no discriminación. Claroscuros de la jurisprudencia interamericana, en Anuario de Derechos Humanos (2007), 3.

FARÍAS, Javiera, Los efectos procesales de la corrección en el ordenamiento jurídico chileno con ocasión de la ley $n^{\circ}$ 20.609, en Ars Boni et Aequi 11 (2014), 1.

FernÁndez, Miguel Ángel, Principio Constitucional de la Igualdad ante la Ley (Santiago, LexisNexis, 2004).

Ferrajoli, Luigi, Derechos y Garantías. La ley del más débil (7a edición, Madrid, Trotta, 2010).

FIss, Owen, Groups and the Equal Protection Clause, en Philosophy and Public Affairs 5 (1976), 2.

Fishkin, Joseph, Bottlenecks. A New Theory of Equal Opportunity (Oxford, Oxford University Press, 2014).

Gerards, Janneke, Grounds of discrimination, en SchieK, Dagmar, Waddington, Lisa y Bell, Mark (editores), Non-discrimination law (Portland, Hart, 2007).

GERARDS, Janneke, Intensity of Judicial Review in Equal Treatment Cases, en Netherlands International Law Review 51 (2004), 2.

GERARDS, Janneke, The discrimination grounds of article 14 of the European convention on Human Rights, en Human Rights Law Review 13 (2013), 1.

Green, Philip, Equality and Democracy (New York, New Press, 1998).

Henríquez, Miriam y NúNEz, José Ignacio, Ley Zamudio: ¿Ponderación o subsunción? comentario a la sentencia rol $n^{\circ}$ 1009-2014 de la Corte de Apelaciones de Concepción, en Revista de Derecho - Escuela de Postgrado (Universidad de Chile) (2014), 6.

Howard, Erica, The Case for a Considered Hierarchy of Discrimination Grounds in EU Law, en Maastricht Journal of European and Comparative Law 13 (2006), 4. 
Huscroft, Grant, Discrimination, Dignity, and the Limits of Equality, en Otago Law Review 9 (2000), 4.

INIIGUEZ, Andrea, La noción de "categoría sospechosa" y el derecho a la igualdad ante la ley en la jurisprudencia del Tribunal Constitucional, en Revista de Derecho de la Universidad Católica de Valparaíso 43 (2014), 2.

Khaitan, Tarunabh, A theory of discrimination law (Oxford, Oxford University Press, 2015).

Loury, Glenn, Why Should We Care About Group Inequality?, en Social Philosophy and Policy 5 (1987), 1.

McColgan, Aileen, Discrimination, equality and the law (Oxford, Hart, 2014).

McCrudden, Christopher y Prechal, Sacha, The Concepts of Equality and Non -Discrimination in Europe: A practical approach (2009) [visible en internet: http:// ec.europa.eu/social/BlobServlet?docId=4553] (2/7/2017).

Mercat-Bruns, Marie, Discrimination at Work. Comparing European, French and American Law (Oakland, University of California Press, 2016).

Michelman, Frank, The Meanings of Legal Equality, en The BlackLetter Journal 3 (1986) Spring.

MuÑoz, Fernando, Estándares Conceptuales, cargas procesales y reparación en el litigio antidiscriminación. Análisis critico de la jurisprudencia sobre Ley Zamudio entre 2012 a 2015, en Revista de Derecho de Valdivia 28 (2015), 2.

Muñoz, Fernando, No a "Separados pero Iguales" en Chile: un Análisis del Derecho Antidiscriminación Chileno a partir de su Primera Sentencia, en Estudios Constitucionales 11 (2013), 2.

NIKOLAIDIS, Charilaos, The right to equality in Europe human rights law (New York, Routledge, 2014).

Pérez, Antonio Enrique, Dimensiones de la Igualdad (2a edición, Madrid, Dykinson, 2007).

PETERS, Anne, Women, quotas and constitutions: a comparative study of affirmative action for women under American, German, EC and international law (London, Kluwer Law International, 1999).

Post, Robert, Prejudicial Appearances: The Logic of American Antidiscrimination Law, en California Law Review 88 (2000), 1.

RéAume, Denise, Discrimination and Dignity, en Louisiana Law Review 63 (2003), 3. Rosales, Cecilia, Acción de no discriminación arbitraria, en Silva, María Pía y Henríquez, Miriam (editores), Acciones protectoras de Derechos Fundamentales (Santiago, LegalPublishing, 2014).

SADURSKI, Wojciech, Equality and Legitimacy (Oxford, Oxford University Press, 2008).

Salvador, María, Las Medidas de Acción Positiva. Principio de Igualdad y Derechos Fundamentales, en SÁnchez, Santiago (editor), En Torno a la Igualdad y la Desigualdad (Madrid, Dykinson, 2009).

SiLva, Alejandro, Tratado de Derecho Constitucional (2a edición, Santiago, Editorial Jurídica de Chile, 2006), XI.

STRAuSs, Marcy, Reevaluating Suspect Classifications, en Seattle University Law Review 35 (2011), 1.

Sunstein, Cass, The Anticaste Principle, en Michigan Law Review 92 (1994), 8.

Ugarte, José Luis, El derecho a la no discriminación en el trabajo (Santiago, LegalPublishing, 2013). 
VIAL, Tomás, La nueva ley antidiscriminación: propuestas para avanzar en su perfeccionamiento, en Anuario de Derechos Humanos (2013), 9.

WallaCe, A note on a famous legal footnote, en The Journal of Politics 25 (1963), 2.

Weber, Mark, Intent in Disability Discrimination Law: Social Science Insights and Comparisons to Race and Sex Discrimination, en University of Illinois Law Review 2016 (2016), 1.

Zapata, Patricio, Justicia Constitucional (Santiago, Editorial Jurídica de Chile, 2008).

ZÚNIGA, Francisco, El principio pro requirente en la sentencia del Tribunal Constitucional sobre la ley orgánica constitucional del Tribunal Constitucional, en Estudios Constitucionales 7 (2009), 2. 